\title{
Introgression of leaf rust and stripe rust resistance from Sharon goatgrass (Aegilops sharonensis Eig) into bread wheat (Triticum aestivum L.)
}

\author{
E. Millet, J. Manisterski, P. Ben-Yehuda, A. Distelfeld, J. Deek, A. Wan, X. Chen, and B.J. Steffenson
}

\begin{abstract}
Leaf rust and stripe rust are devastating wheat diseases, causing significant yield losses in many regions of the world. The use of resistant varieties is the most efficient way to protect wheat crops from these diseases. Sharon goatgrass (Aegilops sharonensis or AES), which is a diploid wild relative of wheat, exhibits a high frequency of leaf and stripe rust resistance. We used the resistant AES accession TH548 and induced homoeologous recombination by the ph1b allele to obtain resistant wheat recombinant lines carrying AES chromosome segments in the genetic background of the spring wheat cultivar Galil. The gametocidal effect from AES was overcome by using an "anti-gametocidal" wheat mutant. These recombinant lines were found resistant to highly virulent races of the leaf and stripe rust pathogens in Israel and the United States. Molecular DArT analysis of the different recombinant lines revealed different lengths of AES segments on wheat chromosome 6B, which indicates the location of both resistance genes.
\end{abstract}

Key words: Aegilops sharonensis, wheat, recombinant lines, leaf rust resistance, stripe rust resistance, DArT mapping.

Résumé : Les rouilles brunes et jaunes sont des maladies dévastatrices chez le blé puisqu'elles causent d'importantes pertes de rendement dans plusieurs régions du monde. L'emploi de variétés résistantes est le moyen le plus efficient de protéger le blé de ces maladies. L'égilope de Sharon (Aegilops sharonensis ou AES), une espèce diploïde sauvage apparentée au blé, présente une haute fréquence de résistance aux rouilles brunes et jaunes. Les auteurs ont employé une accession résistante de l'AES, TH548, et induit de la recombinaison homéologue à l'aide de l'allèle ph1b pour obtenir des lignées recombinantes de blé dotées de résistance grâce à des segments chromosomiques de l'AES introduits dans le fond génétique du cultivar de blé de printemps Galil. L'effet gamétocide de l'AES a été surmonté en employant un blé mutant " anti-gamétocide 》. Ces lignées recombinantes étaient résistantes à des races très virulentes des rouilles brunes et jaunes en Israël et aux États-Unis. Des analyses DArT réalisées sur les différentes lignées recombinantes ont révélé que les segments chromosomiques de l'AES introduits sur le chromosome 6B du blé étaient de différentes longueurs, ce qui a permis de déduire l'emplacement des deux gènes de résistance. [Traduit par la Rédaction]

Mots-clés : Aegilops sharonensis, blé, lignées recombinantes, résistance à la rouille brune, résistance à la rouille jaune, cartographie à l'aide de marqueurs DArT.

\section{Introduction}

Leaf rust, caused by Puccinia triticina Erikss., and stripe (yellow) rust, caused by Puccinia striiformis Westend. f. sp. tritici Erikss., are major wheat diseases. Leaf rust can cause yield losses ranging from $25 \%$ to $90 \%$ (Kolmer et al. 2009) and stripe rust can cause $100 \%$ yield loss, but often ranges from $10 \%$ to $70 \%$ (Chen 2005). In recent years, stripe rust outbreaks were reported in Australia, China, India, Pakistan, Central and West Asia, the Middle East, North Africa, and USA, indicating virulence changes in the pathogen (Wellings et al. 2012). Recent research also indicates that new stripe rust strains have become adapted to higher temperatures (Milus et al. 2006). Although fungicides can control both rust diseases, the additional input costs and potential for negative environmental impacts are serious drawbacks to this strategy. The use of resistant varieties is the most efficient and economical way to control these diseases; however, many of the resistance genes in these varieties have proven ephemeral in widescale deployment. To supplement the genetic diversity of leaf rust and stripe rust resistance in wheat, new genetic resources from the primary, secondary, and tertiary gene pools of wheat should be exploited.

Sharon goatgrass (Aegilops sharonensis Eig) (AES) is a wild diploid (genome $\mathrm{S}^{\text {sh }} S^{\text {sh }} ; 2 n=14$ ) relative of wheat. It is native to the coastal plain of Israel and south Lebanon, growing mostly on stabilized dunes. Work done by Olivera et al. (2007) on a representative sample of AES lines collected in Israel and data from the Institute of Cereal Crops Improvement (ICCI) at Tel Aviv University (Anikster et al. 2005) revealed that many accessions are highly resistant to leaf rust or stripe rust pathogens. A recent evaluation of 1800 newly collected AES accessions at the ICCI confirmed the high frequency of resistance to these diseases in the species (J. Manisterski, unpublished).

Received 9 January 2014. Accepted 7 August 2014.

Corresponding Editor: J.P. Gustafson.

E. Millet, J. Manisterski, and P. Ben-Yehuda. Institute for Cereal Crops Improvement, Tel Aviv University, Tel Aviv 69978, Israel.

A. Distelfeld and J. Deek. Department of Molecular Biology and Ecology of Plants, Tel Aviv University, Tel Aviv 69978, Israel.

A. Wan. Department of Plant Pathology, Washington State University, Pullman, WA 99164-6430, USA.

X. Chen. USDA-ARS, Wheat Genetics, Quality, Physiology and Disease Research Unit; and Department of Plant Pathology, Washington State University, Pullman, WA 99164-6430, USA.

B.J. Steffenson. Department of Plant Pathology, University of Minnesota, St. Paul, MN 55108, USA.

Corresponding author: E. Millet (e-mail: eitan.millet@weizmann.ac.il). 
Moreover, genetic analysis of a number of these lines (Olivera et al. 2008) demonstrated monogenic inheritance of the resistances. Hence, transferring single allele(s) from AES is expected to confer resistance to recipient wheat lines.

Gene transfer from AES is a complex task. Technical problems (e.g., timing of flowering, time of anther dehiscence) and inherent low crossability with wheat result in very low hybrid seed set. Thereafter, pairing and chromosome segment exchange is rare, requiring use of the $p h 1 b$ allele to induce homoeologous pairing.

AES also may possess gametocidal (Gc) genes (Maan 1975; Endo 1985). Only few AES accessions have been used in genetic studies (B. Friebe and T. Endo, personal communication), but all of them showed a gametocidal effect as reflected in the failure to obtain the whole pure series of addition lines of AES. The finding that chromosome $4 S^{\text {sh }}$ was always included in the breeding progenies (Zhang et al. 2001) supports the contention that Gc genes cause preferential transmission of their hosting chromosome. Their presence in a plant is accompanied by chromosome breakage of gametes not carrying the Gc genes, ultimately leading to semisterile spikes.

We developed a comprehensive procedure that addresses the major obstacles in gene transfer from AES into wheat. A ph1b wheat mutant was used to induce recombination. Additionally, an "anti-gametocidal" wheat mutant (Friebe et al. 2003) was used to obtain regular chromosome segregation rather than preferential transmission of the chromosome carrying the gametocidal gene.

\section{Materials and methods}

\section{Plant and pathogen material}

Accession TH548 of AES was collected in Palmahim, Israel (about $15 \mathrm{~km}$ south of Tel Aviv; Millet et al. 2006), and selected because of its seedling resistance to either leaf rust (isolate \#52624; virulence/avirulence (V/Av) formula $\operatorname{Lr} 1,3,24,26,10,18,21,23,15$ / Lr2a,2c,9,16,3ka,11,17,30) or stripe rust (isolate \#5006; V/Av Yr6,7,8,9,11,12,17,19,sk,18,A/Yr1,5,10,15,24,26,sp). Both isolates represent highly virulent pathogen races.

The spring wheat cultivar Galil was selected as the recipient parent because of its high productivity and susceptibility to these pathogen isolates.

The wheat $p h 1 b(\mathrm{Mph})$ mutant in the genetic background of the wheat cultivar Chinese Spring (CS) was originally obtained from the late E.R. Sears.

The anti-gametocidal (AG) mutant was obtained courtesy of B. Friebe (Kansas State University, Manhattan, Kans.). This line, also in a CS background, has a homoeologous distal translocation $4 S^{\text {sh }} \mathrm{L}$ of AES into the wheat $4 \mathrm{BL}$ arm (T4BS-4BL- $4 S^{\text {sh }} \mathrm{L}$ ) carrying an ethyl methanesulfonate (EMS)-mutated $G c 2$ allele ( $G c 2^{\text {mut; }}$; Friebe et al. 2003). From heterozygous $G c 2^{m u t} / G c 2$ plants, the transmission of chromosomes carrying these alleles is regular (random) rather than preferential, as for the chromosome with the Gc2 allele.

\section{Seedling resistance evaluation}

Leaf rust and stripe rust inoculation and evaluation tests in Israel

Seedlings of each generation were tested and selected for leaf rust and stripe rust resistance. Plants were sown and grown in small pots in a temperature-controlled greenhouse at $22 \pm 2{ }^{\circ} \mathrm{C}$. Seven to 10 days after planting, seedlings were inoculated with a suspension of leaf rust or stripe rust urediniospores in a lightweight mineral oil (Soltrol 170). After the oil on the inoculated plants was allowed to evaporate, the plants were incubated overnight in a dew chamber at $18^{\circ} \mathrm{C}$ for leaf rust and $9^{\circ} \mathrm{C}$ for $16 \mathrm{~h}$ in dark followed by $15{ }^{\circ} \mathrm{C}$ in light for stripe rust. Leaf rust-inoculated plants were kept for 12-14 days in the greenhouse and were scored for infection type (IT) on a standard 0 to 4 scale. ITs of 0 to 2 were considered indicative of a resistant response and 3 to 4 as a susceptible response. Stripe rust-inoculated plants remained in a $15{ }^{\circ} \mathrm{C}$ growth chamber with a $12 \mathrm{~h}$ light/12h dark regime for 14-17 days, after which ITs were scored using the same scale used for leaf rust.

\section{Reaction to stripe rust in Pullman, Washington}

The AES-wheat recombinant lines were tested for reaction to stripe rust at the seedling stage under controlled conditions following the procedure described by Chen and Line (1992). Four races of P. striiformis f. sp. tritici (PST-43, PST-100, PST-114, and PST127), which collectively cover all virulence factors identified thus far in the USA and represent predominant races (Chen 2005; Chen et al. 2010), were used in the tests. Seedlings at the two-leaf stage were inoculated with a mixture of fresh urediniospores and talc (Sigma, St. Louis, Mo., USA) at a 1:20 ratio. The inoculated plants were incubated for $24 \mathrm{~h}$ in a dew chamber at $10{ }^{\circ} \mathrm{C}$ without light, and then moved to a growth chamber under a diurnal temperature cycle gradually changing from $4{ }^{\circ} \mathrm{C}$ at $02: 00$ to $20^{\circ} \mathrm{C}$ at $14: 00$ with a $16 \mathrm{~h}$ light/8 h dark cycle. About 20-22 days after inoculation, the ITs of each plant were recorded using a 0 to 9 scale, with 0 indicating no visible symptoms and 9 high susceptibility (Line and Qayoum 1992).

\section{Reaction to leaf rust in St. Paul, Minnesota}

To further characterize the resistance spectrum of AES lines for possible use in US breeding programs, an additional leaf rust resistance test was made with race TFBJQ (isolate US1-1) of P. triticina. Race TFBJQ is unique in that it possesses virulence for $L r 21$, a resistance gene widely used in hard red spring wheat cultivars in the USA and now rendered ineffective with the appearance of Lr21-virulent P. triticina isolates. Seedlings of the AES-wheat recombinant lines and controls were inoculated with urediniospores of race TFBJQ suspended in a lightweight mineral oil (approximately $0.014 \mathrm{mg}$ of spores per plant). Following inoculation, plants were transferred to mist chambers and incubated for $16 \mathrm{~h}$ in darkness at $18-21{ }^{\circ} \mathrm{C}$ and approximately $100 \%$ relative humidity (RH). After the mist period, plants were allowed to slow dry for $4 \mathrm{~h}$ before being placed in a growth chamber at $18-21^{\circ} \mathrm{C}$ with a $14 \mathrm{~h}$ photoperiod. Twelve days after inoculation, plants were evaluated for their ITs based on the 0 to 4 scale of Long and Kolmer (1989).

\section{Gene transfer procedure}

The procedure for gene transfer is summarized in Fig. 1. In 2005, Mph was pollinated by AES accession TH548, and few seeds were obtained. Two seeds were germinated (expected genome BADS ${ }^{\text {sh }}$ ) and developed into apparently self-sterile plants. These plants were pollinated by the AG mutant and produced 10 seeds. Some spikes were also pollinated by Galil because of the lack of AG pollen, and they produced 12 seeds. Offspring of these crosses segregated for reaction to stripe rust isolate \#5006: four seedlings from the cross with the AG mutant and five from the cross with Galil were classified as resistant (IT 0 ; on the 0 to 4 scale) and grown. Each of these plants represents a different recombination event and was labeled by a recombinant line number. These plants were pollinated by the other parent (either Galil or AG) and yielded the $\mathrm{F}_{1}$ generation.

Seedlings at the $F_{1}$ generation were phenotyped against stripe rust isolate \#5006 and leaf rust isolate \#526-24. Out of 55 seedlings tested, two seedlings were found resistant to both diseases, 10 were resistant only to stripe rust, and three only to leaf rust.

Resistant plants were used in four more backcrosses (BCs) using Galil as a recurrent parent. Each generation was accompanied by disease phenotyping to the pathogen for which the $\mathrm{F}_{1}$ recombinant line was resistant. In addition to resistance, we selected $\mathrm{BC}$ plants for agronomic appearance and spike fertility. For each recombinant line, the best plants were selected to represent the line and were labeled by the line number. More identification digits were added to the line number throughout the $\mathrm{BC}$ generations as used in Tables 1 and 2 and in Figs. 2 and 3. 
Fig. 1. Procedure for the transfer of a disease resistance gene $(R)$ from Aegilops sharonensis to wheat using a haploid hybrid with homoeologous

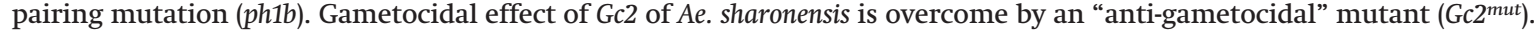

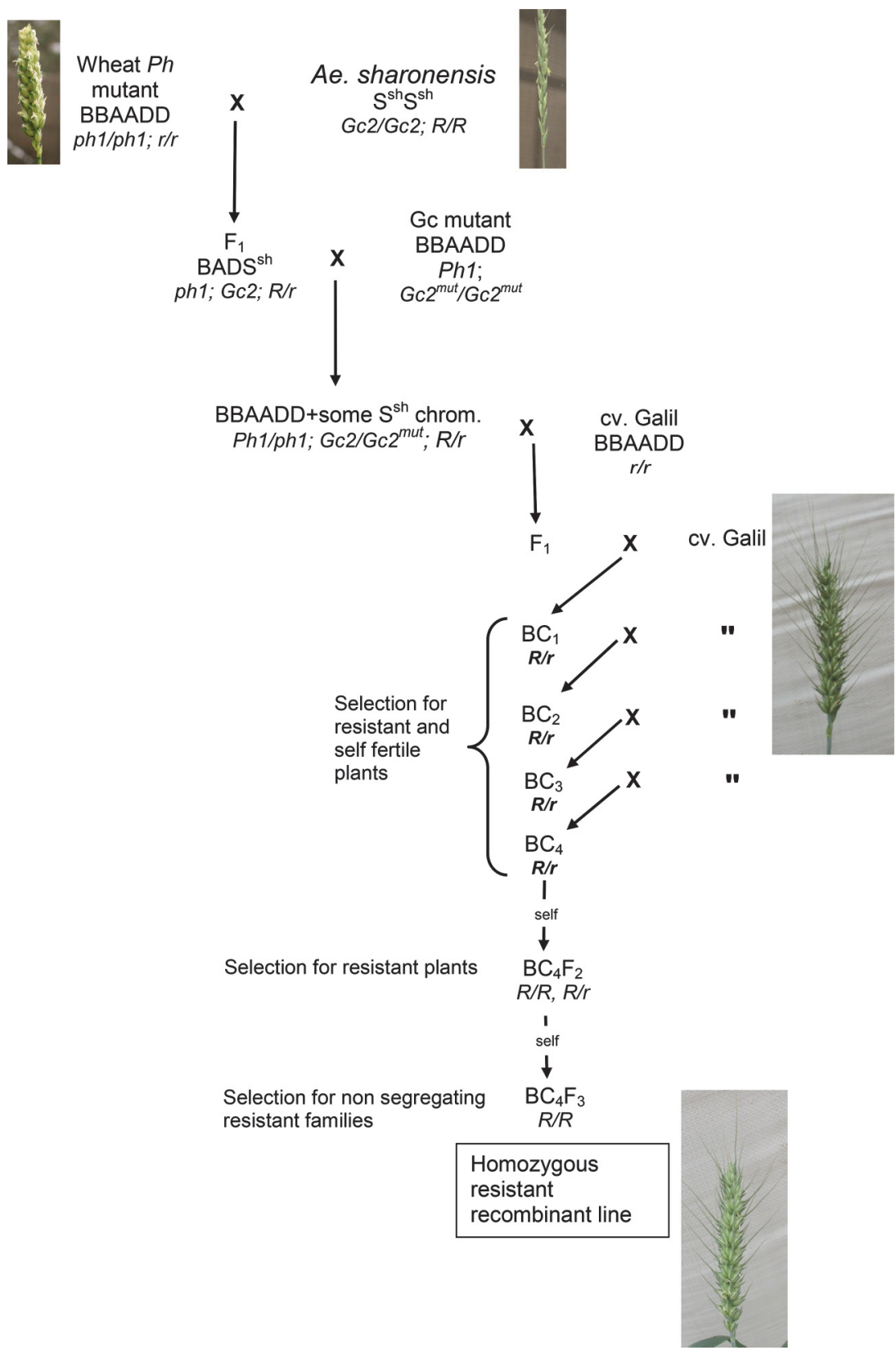

At $\mathrm{BC}_{3}$ and $\mathrm{BC}_{4}$, progenies of resistant plants were allowed to self-pollinate. Resistant $\mathrm{F}_{2}$ seedlings were selected, and 20 of their $\mathrm{F}_{3}$ seeds were phenotyped for their disease reaction. $\mathrm{BC}_{3} \mathrm{~F}_{3}$ and $\mathrm{BC}_{4} \mathrm{~F}_{3}$ families having only resistant seedlings were considered as homozygous resistant.

\section{DArT mapping}

\section{DNA extraction}

DNA was extracted from 4-5 putatively homozygous $\mathrm{BC}_{4} \mathrm{~F}_{3}$ plants of four lines (five genotypes, two belonging to the same line) that were initially selected for their leaf rust resistance and four lines (five genotypes) that were initially selected for their stripe rust resistance.

High-quality genomic DNA was extracted from $0.3-0.5 \mathrm{~g}$ of freeze-dried leaf tissue from young leaves using a modified cetyltrimethyl-ammonium bromide (CTAB) method of Doyle and Doyle
(1987). Plant material was ground in a Tissue-lyser (Geno/Grinder) with $1 \mathrm{~mL}$ CTAB extraction buffer containing $41.7 \%$ extraction buffer $(0.35 \mathrm{~mol} / \mathrm{L}$ sorbitol, $0.1 \mathrm{~mol} / \mathrm{L}$ Tris $\mathrm{HCl}$, and $5 \mathrm{mmol} / \mathrm{L}$ EDTA), $41.7 \%$ lysis buffer $(0.2 \mathrm{~mol} / \mathrm{L}$ Tris $\mathrm{HCl}, 0.05 \mathrm{~mol} / \mathrm{L}$ EDTA, $2 \mathrm{~mol} / \mathrm{L} \mathrm{NaCl}$, and 2\% CTAB), 16.7\% Sarcosyl (5\%), 0.5\% Sodium-bisulfite, and $2 \%$ PVP-40 preheated to $65{ }^{\circ} \mathrm{C}$.

Samples were incubated at $65^{\circ} \mathrm{C}$ for $1 \mathrm{~h}$ with occasional gentle swirling and deproteinized with $0.8 \mathrm{~mL}$ of chloroform/isoamylalcohol (24:1). The resulting mixture was vigorously shaken for $15 \mathrm{~min}$ and then centrifuged at $10000 \mathrm{~g}$ for $20 \mathrm{~min}$. DNA was precipitated from the aqueous phase by adding $1 \mathrm{~mL}$ of ice-cold isopropanol and mixing by gently inverting the tubes. The tubes were stored at $-20{ }^{\circ} \mathrm{C}$ overnight and then centrifuged at $10000 \mathrm{~g}$ for $30 \mathrm{~min}$. The DNA pellet was washed with $70 \%$ ethanol, dried, and finally dissolved in $250 \mu \mathrm{L}$ of $1 \times$ TE ( $10 \mathrm{mmol} / \mathrm{L}$ Tris $\mathrm{HCl}, 1 \mathrm{mmol} / \mathrm{L}$ EDTA) by overnight incubation at room temperature. 
Table 1. Seedling infection types of Aegilops sharonensis-wheat recombinant lines tested at a low temperature profile with races PST-43, PST-100, PST-114, and PST-127 of Puccinia striiformis f. sp. tritici under controlled greenhouse conditions (Pullman, Washington, 2007).

\begin{tabular}{llllll}
\hline & & \multicolumn{4}{l}{ Infection type (no. of plants) by PST races* } \\
\cline { 3 - 6 } Line & $\begin{array}{l}\text { Selected for } \\
\text { resistance to }\end{array}$ & PST-43 & PST-100 & PST-114 & PST-127 \\
\hline Galil (A) & Parental line & $1(5)$ & $1(4), 3(1)$ & $8(5)$ & 2 to 3 (5) \\
Galil (B) & Parental line & $1(5)$ & $1(3), 8(2)$ & $8(5)$ & $1(3), 3(1)$ \\
RL-17-1-3 & Leaf rust & $1(5)$ & 1 to $2(5)$ & $7(3), 2(2)$ & $1(3), 3(2)$ \\
RL-17-1-9 & Leaf rust & $1(5)$ & $1(4)$ & $7(3), 2(2)$ & $1(5)$ \\
RL-610-5-5 & Leaf rust & $1(4)$ & $1(4)$ & $7(3), 2(2)$ & $1(5)$ \\
RY-24-4-2 & Stripe rust & $1(5)$ & $1(5)$ & 3 to 4 (5) & $1(5)$ \\
RY-32-1-1 & Stripe rust & $1(5)$ & $1(4)$ & $2(5)$ & $1(5)$ \\
RY-41-6-2 & Stripe rust & $1(5)$ & 1 to 2 $2(4)$ & 2 to 3 (5) & $1(5)$ \\
RY-63-7-1 & Stripe rust & $1(5)$ & $1(5)$ & $2(5)$ & $1(5)$ \\
RY-74-4-3 & Stripe rust & $2(5)$ & $1(5)$ & 2 to 3 (5) & $1(5)$ \\
Lemhi & Susceptible check & $8(5)$ & $8(6)$ & $8(5)$ & $8(5)$ \\
\hline *Infection types scored according to a 0 to 9 scale. Refer to Chen (2005) and Chen et al. (2010) for the virulence/ \\
avirulence patterns of the tested races.
\end{tabular}

Table 2. Reaction of three $\mathrm{BC}_{3} \mathrm{~F}_{4}$ lines that were originally selected for resistance to the Israeli leaf rust isolate \#526-24 to the American leaf rust race TFBJQ with Lr21 virulence (St. Paul, Minnesota, 2012).

\begin{tabular}{|c|c|c|c|}
\hline Line & $\begin{array}{l}\text { Infection type* } \\
\text { (no. of plants) }\end{array}$ & $\begin{array}{l}\text { General } \\
\text { reaction }{ }^{\dagger}\end{array}$ & Comment \\
\hline \multirow[t]{2}{*}{ Galil } & 2 to $3-(3)$ & MS & Minor variation in infection types \\
\hline & 1 to $2(1)$ & MR & \\
\hline \multirow[t]{4}{*}{ RL-17-1-3 } & $1=(3)$ & $\mathrm{R}$ & Clear and extreme segregation for infection types \\
\hline & $0 ; 1-(1)$ & $\mathrm{R}$ & \\
\hline & 2 to $3-(1)$ & MS & \\
\hline & $3(1)$ & S & \\
\hline RL-17-1-9 & $0 ;$ to $0 ; 1=(8)$ & HR to $\mathrm{R}$ & Minor variation in infection types \\
\hline RL-610-5-3 & $0 ;$ to $0 ; 1=(8)$ & HR to $\mathrm{R}$ & Minor variation in infection types \\
\hline Little Club & $4(8)$ & $\mathrm{S}$ & Consistently high infection types \\
\hline
\end{tabular}

DNA quality was checked on a $0.8 \%$ agarose gel and quantified using a NanoDrop spectrophotometer (Maestrogen Inc., Las Vegas, Nev., USA). The concentration of DNA samples was adjusted to $50-70 \mathrm{ng} / \mu \mathrm{L}$ and stored at $-20{ }^{\circ} \mathrm{C}$.

Samples were shipped to Diversity Arrays Technology Pty. Ltd. (Yarralumla, Australia) following their instructions (see, www. diversityarrays.com).

\section{DArT analysis}

About 1000 wheat markers, but very few (out of about 1000) AES markers were mapped on chromosomes by DArT Pty. Ltd. Additional mapping data on AES markers were gratefully obtained from M. Moscou, The Sainsbury Laboratory, John Innes Centre, Norwich, UK. These concensus map data were produced from three segregating AES populations. The markers were assembled into linkage groups with the aid of SNP data (M. Moscou, personal communication). In a number of cases, polymorphisms existed between AES and the wheat cultivar Galil, but not between AES and the wheat cultivar CS.

\section{Map drawing}

Polymorphic DArT markers with known map location and linkage groups (segments) were plotted using MapChart 2.2 software (Voorrips 2002). Three cases of marker substitution were considered as follows: absence of a wheat (Galil and CS) marker in the recombinant lines; absence of a wheat marker in a recombinant line and in CS, but not in Galil (which prevents an unequivocal determination that AES chromatin substitutes for wheat chroma- tin); and presence of an AES (aePt) or a wheat (wPt) marker in a recombinant line only, but not in the wheat parents (Galil and CS). The different linkage groups that were defined here (Figs. 2 and 3) to increase map resolution do not necessarily reflect the complete chromosome constitution because of large gaps between markers in certain regions.

\section{Results}

\section{Dart mapping}

Informative, polymorphic markers were found almost exclusively on chromosome $6 \mathrm{~B}$ and were usually identical for all of the plants of a line. Only a few other markers were sporadically mapped to other locations, but these were not found consistently in all of the plants of a line. Using the DArT marker consensus map data obtained from A. Kilian, DArT Pty. Ltd., 67 wheat markers that were used in this study were mapped on chromosome 6B, but Galil had only 38 markers. These markers were indicative of the presence of Galil chromatin and their absence served as indication of alien substitution. In addition, using the DArT AES map provided by courtesy of M. Moscou (unpublished), 18 aePt markers on chromosome $6^{\text {sh }}$ of AES were informative. The markers were not evenly distributed and tended to concentrate between the short arm telomere (distance 0 ) and $16.4 \mathrm{cM}$ and then between 30 and $71 \mathrm{cM}$ (Figs. 2 and 3). In many cases, more than one marker was mapped to the same position. 
Fig. 2. DArT marker map of the wheat cultivar Galil and its derived leaf rust resistant recombinant lines. Linkage groups are colored: yellow, Galil; green, AES marker alleles present; blue, wheat (Galil and CS) marker alleles are missing; red, Galil marker alleles are missing in the recombinant lines and in CS. White segments reflect missing data between sparse markers. Chromotypes are denoted by small letters (a-c). The majority of wheat DArT markers and map locations were obtained from A. Kilian (Diversity Arrays Technology Pty. Ltd.) (unpublished). The Ae. sharonensis markers and map locations were provided by M. Moscou (unpublished).

\section{Galil-6B}

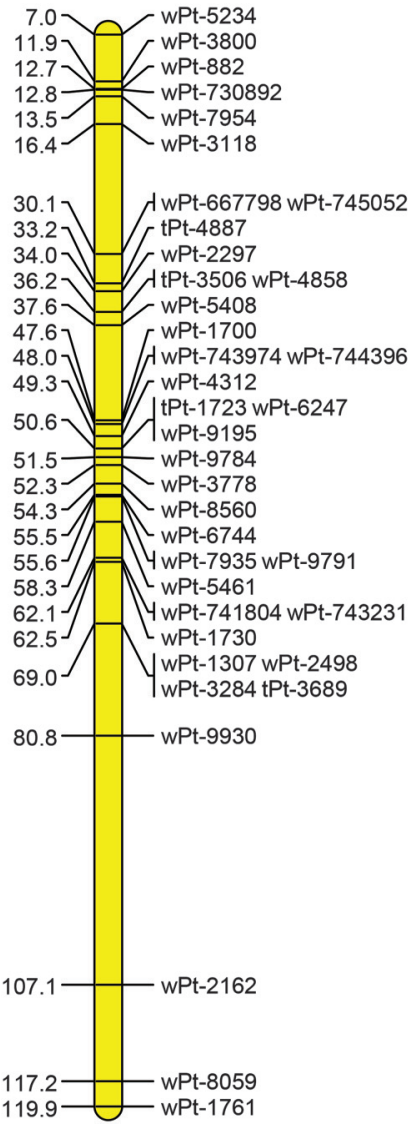

6B-RL-17-6

a

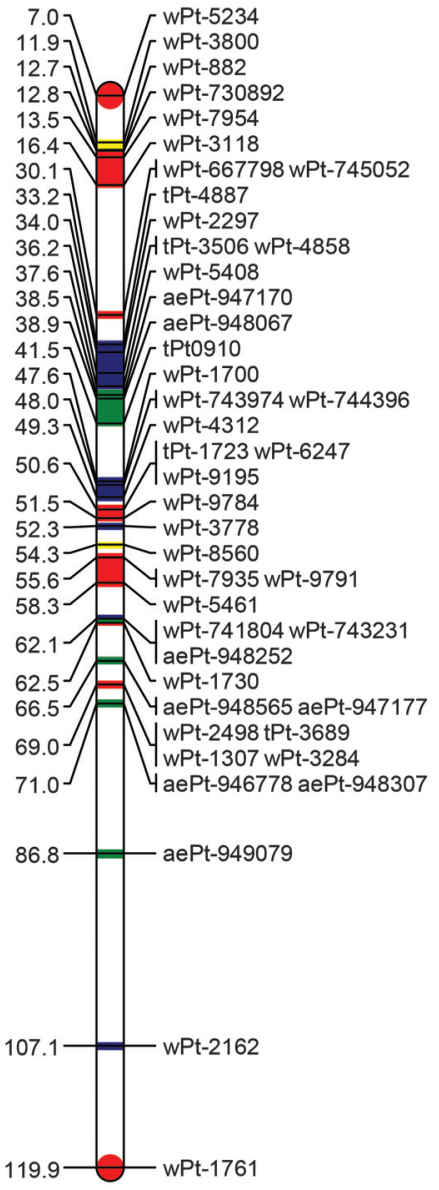

6B-RL-76-2 and 86-4

b

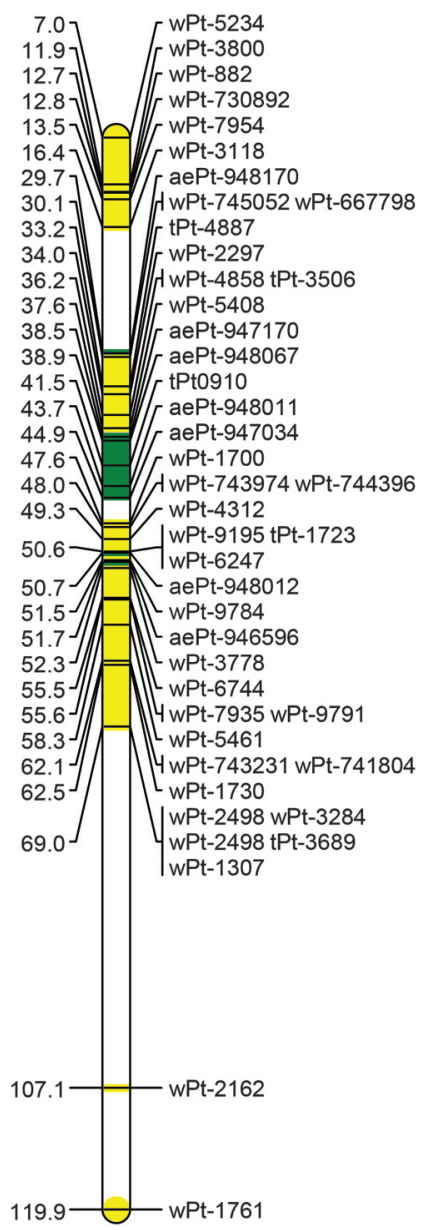

6B-RL-510-1

C

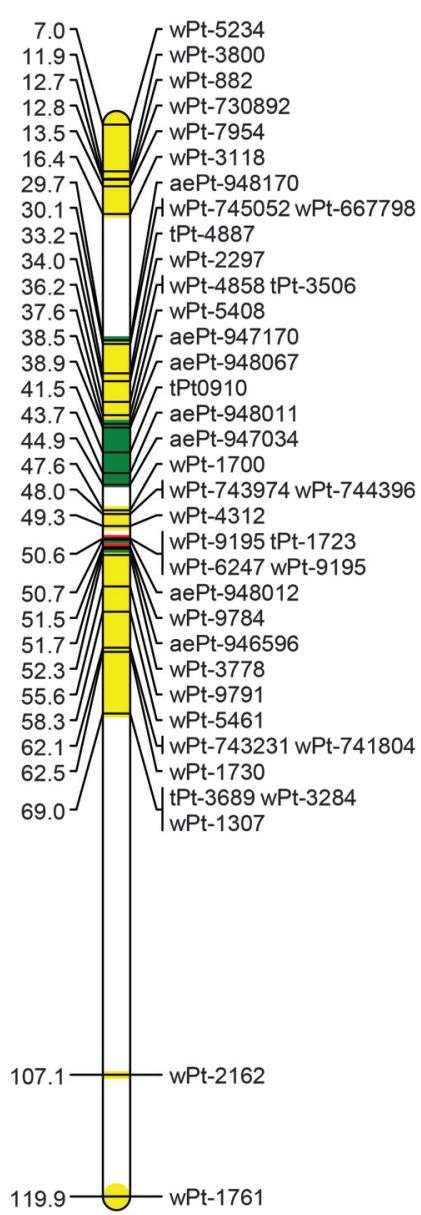

\section{Leaf rust resistant lines}

One $\mathrm{BC}_{4}$ leaf rust resistant line (RL-17) was derived from pollination of the haploid hybrid $\left(\mathrm{F}_{1} \mathrm{Mph} \times \mathrm{AES}\right)$ by the AG mutant. This line is characterized by large AES segment(s) spanning together the whole $6 \mathrm{~B}$ chromosome. Nevertheless, two Galil markers were still present at positions 12.7 and $54.3 \mathrm{cM}$ (chromotype a; Fig. 2). Three other leaf rust resistant lines (RL-76, RL-86, and RL-510) were derived from a cross of the haploid hybrid with Galil before its offspring were pollinated by the AG mutant. All of these three lines had a similar short intercalary AES region of $22 \mathrm{cM}$ on chromosome 6B; RL-510 being different from the two other lines by the absence of a couple of wheat markers at $50.6 \mathrm{cM}$ (chromotypes $\mathrm{b}$ and c). Yet, within this region, two segments of Galil markers were found (approximately $30-38 \mathrm{cM}$ and $47-50 \mathrm{cM}$ ). However, only three AES markers, namely aePt947170, aePt948067, and tPt0910 mapping to 38.5, 38.9, and $41.5 \mathrm{cM}$, respectively, were found in common with all of the recombinant chromotypes. This suggests that these AES markers are linked to the leaf rust resistance gene. All of these leaf rust resistant lines were consistently highly resistant to leaf rust isolate \#526-24.

\section{Stripe rust resistant lines}

All of the $\mathrm{BC}_{4}$ stripe rust resistant lines were derived from pollination of the haploid hybrid $\left(\mathrm{F}_{1} \mathrm{Mph} \times \mathrm{AES}\right)$ by the AG mutant followed by pollination of the offspring by Galil. The chromosome constitution of lines RY-32-3-3 and RY-41 was similar to that of line RL-17 (AES segment(s) spanning the whole 6B chromosome with only two Galil markers; chromotype d, Fig. 3). Line RL-32-3-14 had also a long AES insertion (about $74 \mathrm{cM}$ ), but its telomeres were typically of Galil type. The two other lines showed similar chromotypes (f and g). They both had an intercalary AES region between 38.5 and $48 \mathrm{cM}$ followed by another region from 48 to $87 \mathrm{cM}$ of mosaics of wheat and AES markers. Several distinct AES markers were common to all recombinant chromotypes: aePt947170 (mapped on $38.5 \mathrm{cM}$ ), tPt0910 (41.5 cM), aePt948252 (62.1 cM), aePt948565 and aePt947177 (66.5 cM), and aePt949079 (86.8 cM). It is noteworthy that only aePt947170 and tPt0910 were common to all the leaf rust resistant chromotypes too. All of these lines were consistently highly resistant to stripe rust isolate \#5006.

Resistance of lines to North American races of P. striiformis f. sp. tritici

Five homozygous stripe rust resistant $\mathrm{BC}_{3} \mathrm{~F}_{4}$ lines and three leaf rust resistant $\mathrm{BC}_{3} \mathrm{~F}_{4}$ lines were phenotyped in 2007 for their reac- 
Fig. 3. DArT marker map of the wheat cultivar Galil and its derived stripe rust resistant recombinant lines. Linkage groups are colored: yellow, Galil; green, AES marker alleles present; blue, wheat (Galil and CS) marker alleles are missing; red, Galil marker alleles are missing in the recombinant lines and in CS. White segments reflect missing data between sparse markers. Chromotypes are denoted by small letters (d-g). The majority of wheat DArT markers and map locations were obtained from A. Kilian (Diversity Arrays Technology Pty. Ltd.) (unpublished). The Ae. sharonensis markers and map locations were provided by M. Moscou (unpublished).

6B-RY-32-3-14

e

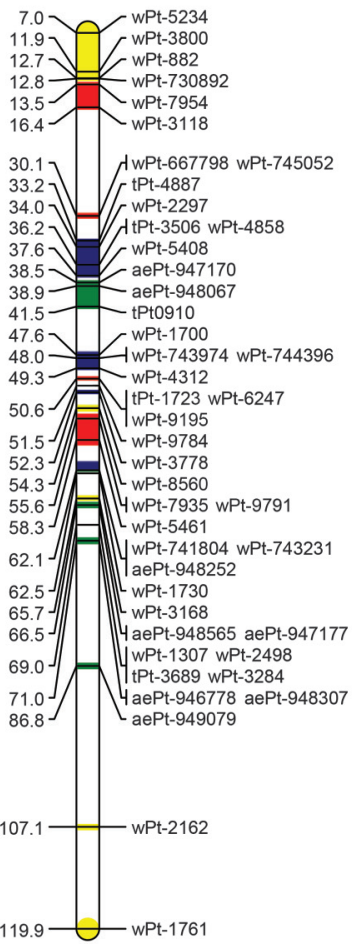

6B-RY-14-1-7

f

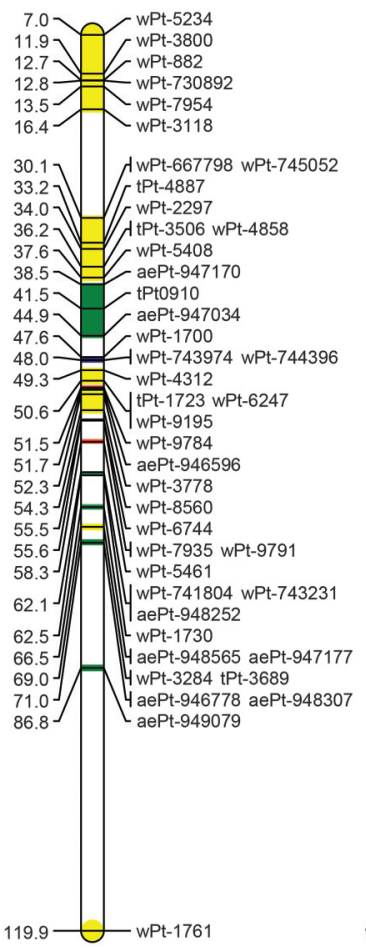

6B-RY-24-6-2

g
6B-Galil

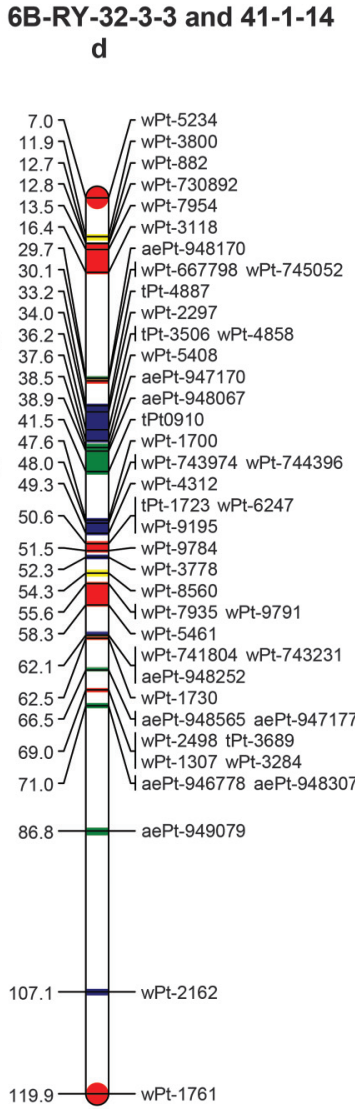

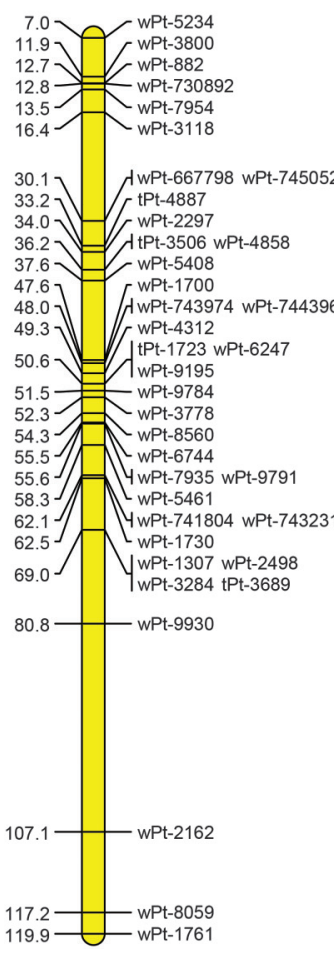

tion against four North American races of the stripe rust pathogen in Pullman, Washington. The results are given in Table 1.

As can be seen, the resistance of Galil to all PST races, except PST-114, masked the reaction of the recombinant lines to these races. However, Galil was highly susceptible to PST-114. All of the stripe rust resistant selected lines were resistant to PST-114. Most of these lines exhibited IT 2, but line RY-24-4-2 exhibited IT 3 to 4 on the 0 to 9 scale. The five seedlings of each of the three leaf rust resistant lines segregated into three resistant and two susceptible individuals in response to stripe rust PST-114.

Race PST-114 was first detected in Washington State in 2004 and was the top one or top four predominant races in the USA from 2005 to 2009. Although it has high frequency in the USA, PST-114 has been mostly restricted in the Pacific Northwest region (Washington, Idaho, Oregon, and western Montana) of the USA. The major characteristic of PST-114 is its combination of virulences to Yr8 and Yr9 and Yr10.

\section{Resistance of the lines to North American leaf rust}

Three homozygous leaf rust resistant $\mathrm{BC}_{3} \mathrm{~F}_{4}$ lines were phenotyped in 2007 for their reaction against a North American race of P. triticina with $L r 21$ virulence in St. Paul, Minnesota. The results are given in Table 2 .

Galil expressed reactions ranging from moderately susceptible to moderately resistant to the race with Lr21 virulence. Hence, its genetic background masked the reaction of the recombinant lines. Even so, two of the lines (RL-17-1-9 and RL-610-5-3) exhibited highly resistant responses and one line (RL-17-1-3) segregated for the response.
Lr21 is present in hard red spring wheat cultivars occupying $50 \%$ of the wheat acreage in North Dakota and Minnesota.

\section{Discussion}

Different procedures have been utilized to transfer genes from wild relatives to wheat (e.g., Feldman 1983; Millet 2007; Millet et al. 2007; Qi et al. 2007; Kilian et al. 2011), many of which included production of an amphiploid by chromosome duplication of the interspecific hybrid and use of the $p h 1 b$ allele to induce homoeologous pairing. A plausible reason for using chromosome duplication is that the low seed set of a haploid hybrid between wheat and an alien species is reduced further in the absence of $\mathrm{Ph} 1$ (Sears 1976, 1977). Nevertheless, using a haploid hybrid with ph1b, few seeds were obtained, which allowed more rapid gene introgressions owing to the reduced number of $\mathrm{BC}$ generations required. Indeed, $\mathrm{BC}_{4}$ plants already recovered the appearance of an agronomically suitable line. Use of a haploid hybrid and at least nine BCs to wheat allowed Marais et al. (2003) to obtain leaf rust and stripe rust resistant plants from AES introgressions without employing $p h 1$, yet the introgressed segment was still too long for practical breeding (Marais et al. 2006) and required further use of ph1 for its reduction (Marais et al. 2010).

It is noteworthy that the method used in this study allows for chromatin exchange between wheat and AES chromosomes, but the alien chromatin is not artificially directed into any of the wheat genomes. Consequently, not only may genetic drag be a drawback, but also the introgressed progenies may suffer from the lack of essential wheat chromatin. Despite these drawbacks, 
the procedure used here yielded fertile resistant $\mathrm{BC}_{4}$ progenies that phenotypically resemble their recurrent parental cultivar Galil (Fig. 1).

No cytological study was done to follow the action of the $G c 2^{\text {mut }}$ as expressed by chromosome breakage in gametes in the segregating families. However, the presence in each family of offspring with low seed set and offspring with complete seed set indicates possible regular segregation of gametes with or without $G c 2$ that allowed us to discard the $G c 2$ gene by selection of fully fertile progenies. To overcome gametocidal effects, Marais et al. (2003) utilized the wheat line W84-17, which proved to somewhat "neutralize" Gc2-associated effects, as a recurrent parent in their recombinant BC progenies.

With the availability of AES maps (Olivera et al. 2013; M. Moscou, unpublished data), DArT mapping is a time and cost effective procedure to assess introgressions. Yet, most of the polymorphic AES DArT markers have not been mapped. Considering the homoeology between wheat $6 \mathrm{~B}$ and $\mathrm{AES} 6 \mathrm{~S}^{\text {sh }}$ chromosomes, we used in many instances the information of absent wheat (cultivar Galil) DArT marker alleles in a tested line as an indication for substitution by AES chromatin. Yet it must be recognized that polymorphic AES markers used in this study were mapped using segregating AES populations, while the wheat DArT markers map was prepared from a segregating population of wheat. Despite the expected synteny between genes of these two closely related species, estimates of the distance between genes within AES and wheat may be species dependent. Hence, the construction of any of the recombinant chromosomes using both AES and wheat DArT markers as they appear in Figs. 2 and 3 may not reflect the exact chromotype composition.

Since on one hand it is expected that recombination is the outcome of homoeologous pairing between wheat and AES and on the other hand a double (or more) crossing over events per chromosome arm are not expected in wheat-alien hybrids (Lukaszewski 1995), it remains unclear why in some regions Galil markers were mixed with AES markers (or lack of wheat markers) as is most prominent in chromotypes e, $\mathrm{f}$, and $\mathrm{g}$. One possible explanation could be the lack of an accurate map that was derived from mapping data of two species.

In cases where both CS and a recombinant line expressed a null allele of a given Galil marker, there is a possibility that Galil chromatin was replaced by CS chromatin (from Mph or AG genotype) and no introgression of AES chromatin occurred.

Almost all of the polymorphic wheat markers associated with the target introgression events in the various lines belonged to chromosome $6 \mathrm{~B}$, and the AES informative markers belonged to $6 S^{\text {sh }}$. These mapping results strongly suggest that wheat chromatin of chromosome 6B was replaced by homoeologous AES chromatin. All of the resistant lines carried $6 S^{\text {sh }}$ segments of various lengths and few chromatin substitutions were common to all lines tested. From correspondence between resistant genotypes and mapping data of the $6 \mathrm{~B}-6 \mathrm{~S}^{\text {sh }}$ recombinants, we concluded that the translocated AES $6 S^{\text {sh }}$ segment(s) carry genes for leaf rust and stripe rust resistance.

The possibility of AG being responsible for the resistance owing to its AES translocation is ruled out since this mutant was found by us to be susceptible (IT 3; on the 0 to 4 scale) both to leaf rust isolate \#526-24 and to stripe rust isolate \#5006. Apparently, the alien translocation from $4 S^{\text {sh }} \mathrm{L}$ (Friebe et al. 2003) does not carry resistance genes against these isolates.

Whether these genes are identical to Lr56 and Yr38 found by Marais et al. (2010) remains to be investigated. That the translocation line described by Marais et al. (2010) possesses resistance gene(s) on wheat chromosome $6 \mathrm{~A}$ is in accordance with our finding that $6 S^{\text {sh }}$ contributed the gene(s). However, Marais et al. (2010) contended that these genes reside on the sub-telomeric region of $6 \mathrm{AL}$, whereas our study suggests a more proximal location. In fact our findings may fit closer to those of Olivera et al. (2013) who mapped a leaf rust resistance locus at $29.8 \mathrm{cM}$ in a cross between resistant (1644) and susceptible (1193) AES accessions. Considering the prevailing synteny between chromosomes $6 \mathrm{~A}$ and $6 \mathrm{~B}$, it is likely that the $\mathrm{Lr}$ and $\mathrm{Yr}$ genes we introgressed from accession TH548 are different from those reported by Marais et al. (2010). To resolve this matter further, higher resolution mapping of the translocated segments is required. Additionally, rust resistance loci in the introgression line of Marais et al. (2010) and those produced in this study will be assessed to an array of diverse leaf rust races to determine if they have the same resistance spectra.

It is also unclear whether or not the leaf rust and the stripe rust resistance genes are tightly linked as was claimed by Marais et al. (2010) for Lr56 and Yr38. Indeed, most of our leaf rust resistant lines were also stripe rust resistant and vice versa, but this was not true for all examined plants (e.g., the segregation of reaction to stripe rust of leaf rust resistant lines; Table 1). Moreover, the fact that in the initial $\mathrm{F}_{1}$ selected plants we found types that were resistant to either leaf rust or stripe rust suggests that the respective rust resistance genes reside at two different loci and can be separated through recombination.

In some recombinant lines, large translocated segments, at least in genetic terms, may negatively affect their overall agronomic performance. However, other recombination lines carried medium to small translocation segments, which may not unduly interfere with their productivity. The yield potential of all selected recombinant lines is currently being evaluated in the field.

\section{Acknowledgement}

This study was supported in part by funds provided through the Lieberman-Okinow Endowment at the University of Minnesota. The additional financial support of the Stephen Lieberman family to E.M. is greatly appreciated. This study also was supported in part by funds to B.J.S. through a grant from the Bill \& Melinda Gates Foundation and the UK Department for International Development to Cornell University for the Borlaug Global Rust Initiative (BGRI) Durable Rust Resistance in Wheat (DRRW) Project. We thank James Kolmer for providing leaf rust race TFBJQ.

\section{References}

Anikster, Y., Manisterski, J., Long, D.J., and Leonard, K.J. 2005. Resistance to leaf rust, stripe rust and stem rust in Aegilops spp. in Israel. Plant Dis. 89: 303-308. doi:10.1094/PD-89-0303.

Chen, X.M. 2005. Epidemiology and control of stripe rust [Puccinia striiformis $\mathrm{f}$. sp. tritici] on wheat. Can. J. Plant Pathol. 27(3): 314-337. doi:10.1080/ 07060660509507230.

Chen, X.M., and Line, R.F. 1992. Inheritance of stripe rust resistance in wheat cultivars used to differentiate races of Puccinia striiformis in North America. Phytopathology, 82: 633-637. doi:10.1094/Phyto-82-633.

Chen, X.M., Penman, L., Wan, A.M., and Cheng, P. 2010. Virulence races of Puccinia striiformis f. sp. tritici in 2006 and 2007 and development of wheat stripe rust and distributions, dynamics, and evolutionary relationships of races from 2000 to 2007 in the United States. Can. J. Plant Pathol. 32(3): 315-333. doi:10.1080/07060661.2010.499271.

Doyle, J.J., and Doyle, J.L. 1987. A rapid DNA isolation procedure for small quantities of fresh leaf tissue. Phytochem. Bull. 19: 11-15.

Endo, T.R. 1985. Two types of gametocidal chromosomes of Ae. sharonensis and Ae. longissima. Jpn. J. Genet. 60: 125-135. doi:10.1266/jjg.60.125.

Feldman, M. 1983. Gene transfer from wild species into cultivated plants. Acta Biol. Yugoslav. Genet. 15: 145-161.

Friebe, B., Zhang, P., Gill, B., and Nasuda, S. 2003. Characterization of a knockout mutation at the Gc2 locus in wheat. Chromosoma, 111: 509-517. doi:10.1007| s00412-003-0234-8. PMID:12684822.

Kilian, B., Mammen, K., Millet, E., Sharma, R., Graner, A., Salamini, F., et al. 2011. Aegilops. In Wild crop relatives: genomic and breeding resources, cereals. Edited by C. Kole. Springer-Verlag, Berlin Heidelberg. pp. 1-76.

Kolmer, J., Chen, X.M., and Jin, Y. 2009. Diseases which challenge global wheat production - the wheat rusts. pp. 89-124. In Wheat: science and trade. Edited by B.F. Carver. Wiley-Blackwell, John Wiley \& Sons, Inc., Ames, Iowa. 569 p.

Line, R.F., and Qayoum, A. 1992. Virulence, aggressiveness, evolution, and distribution of races of Puccinia striiformis (the cause of stripe rust of wheat) in North America, 1968-87. U.S. Department of Agriculture Technical Bulletin No. $1788,44 \mathrm{p}$.

Long, D.L., and Kolmer, J.A. 1989. A North American system of nomenclature for Puccinia triticina. Phytopathology, 79: 525-529. doi:10.1094/Phyto-79-525. 
Lukaszewski, A. 1995. Physical distribution of translocation breakpoints in homoeologous recombinants induced by the absence of the Ph1 gene in wheat and triticale. Theor. Appl. Genet. 90: 714-719. doi:10.1007/BF00222138. PMID: 24174032

Maan, S.S. 1975. Exclusive preferential transmission of an alien chromosome in common wheat. Crop Sci. 15: 287-292. doi:10.2135/cropsci1975.0011183X001500030002x.

Marais, G.F., Pretorius, Z.A., Marais, A.S., and Wellings, C.R. 2003. Transfer of rust resistance genes from Triticum species to common wheat. S. Afr. J. Plant Soil, 20: 193-198. doi:10.1080/02571862.2003.10634934.

Marais, G.F., McCallum, B., and Marais, A.S. 2006. Leaf rust and stripe rust resistance genes derived from Aegilops sharonensis. Euphytica, 149: 373-380. doi:10.1007/s10681-006-9092-9.

Marais, G.F., Badenhorst, P.E., Eksteen, A., and Pretorius, Z.A. 2010. Reduction of Aegilops sharonensis chromatin associated with resistance genes Lr56 and Yr38 in wheat. Euphytica, 171: 15-22. doi:10.1007/s10681-009-9973-9.

Millet, E. 2007. Exploitation of Aegilops species of section Sitopsis for wheat improvement. Isr. J. Plant Sci. 55: 277-287. doi:10.1560/IJPS.55.3-4.277.

Millet, E., Agami, M., Ezrati, S., Manisterski, J., and Anikster, Y. 2006. Distribution of Sharon goat grass (Aegilops sharonensis Eig) in Israel. Isr. J. Plant Sci. 54: 243-248. doi:10.1560/IJPS_54_3_243.

Millet, E., Manisterski, J., and Ben-Yehuda, P. 2007. Exploitation of wild cereals for wheat improvement in the Institute for Cereal Crops Improvement. In Crop Wild Relative Conservation and Use. Edited by N. Maxted, B.V. Ford-Lloyd, S.P. Kell, J.M. Iriondo, E. Dulloo, and E. Turok. CAB International. pp. 554-563.

Milus, E.A., Seyran, E., and McNew, R. 2006. Aggressiveness of Puccinia striiformis f. sp. tritici isolates in south-central United States. Plant Dis. 90: 847-852. doi:10.1094/PD-90-0847.
Olivera, P.D., Kolmer, J.A., Anikster, Y., and Steffenson, B.J. 2007. Resistance of Sharon Goatgrass (Aegilops sharonensis) to fungal diseases of wheat. Plant Dis. 91: 942-950. doi:10.1094/PDIS-91-8-0942.

Olivera, P.D., Millet, E., Anikster, Y., and Steffenson, B.J. 2008. Genetics of resistance to wheat leaf rust, stem rust, and powdery mildew in Aegilops sharonensis. Phytopathology, 98: 353-358. doi:10.1094/PHYTO-98-3-0353. PMID:18944087.

Olivera, P.D., Kilian, A., Wenzl, P., and Steffenson, B.J. 2013. Development of a genetic linkage map for Sharon goatgrass (Aegilops sharonensis) and mapping of a leaf rust resistance gene. Genome, 56(7): 367-376. doi:10.1139/gen-20130065. PMID:24099389.

Qi, L., Friebe, B., Zhang, P., and Gill, B.S. 2007. Homoeologous recombination, chromosome engineering and crop improvement. Chromosome Res. 15: 3-19. doi:10.1007/s10577-006-1108-8. PMID:17295123.

Sears, E.R. 1976. Genetic control of chromosome pairing in wheat. Annu. Rev. Genet. 10: 31-51. doi:10.1146/annurev.ge.10.120176.000335. PMID:797311.

Sears, E.R. 1977. An induced mutant with homoeologous pairing in common wheat. Can. J. Genet. Cytol. 19(4): 585-593. doi:10.1139/g77-063.

Voorrips, R.E. 2002. MapChart: Software for the graphical presentation of linkage maps and QTLs. J. Hered. 93: 77-78. PMID:12011185.

Wellings, C.R., Boyd, L.A., and Chen, X.M. 2012. Resistance to stripe rust in wheat: pathogen biology driving resistance breeding. In Disease resistance in wheat. Edited by I. Sharma. CAB International, pp. 63-83.

Zhang, H., Reader, S.M., Liu, X., Jia, J.Z., Gale, M.D., and Devos, K.M. 2001. Comparative genetic analysis of the Aegilops longissima and Ag. sharonensis genomes with common wheat. Theor. Appl. Genet. 103: 518-525. doi:10.1007| s001220100656. 